\title{
E Research Square \\ Characteristics of Soil Aggregates and Its Organic Carbon in Daxing'anling Forest Region
}

\section{Bing Wang ( $\nabla$ bingweier@hotmail.com )}

Inner Mongolia Agricultural University

\section{Zhiqi Gong}

Inner Mongolia Agricultural University

\section{Qiuliang Zhang}

Inner Mongolia Agricultural University

\section{Research Article}

Keywords: Daxing'anling, soil aggregates, organic carbon, spatial variation

Posted Date: October 20th, 2021

DOl: https://doi.org/10.21203/rs.3.rs-845068/v1

License: (1) This work is licensed under a Creative Commons Attribution 4.0 International License. Read Full License 


\section{Characteristics of soil aggregates and its organic 2 carbon in Daxing'anling forest region}

3 Bing Wang, Zhiqi Gong, Qiuliang Zhang*

4 Forestry College, Inner Mongolia Agricultural University, Hohhot 010019, China;

$5 \quad *$ Corresponding author at: Forestry College, Inner Mongolia Agricultural University, Xinjian East Street No.275,

6 Hohhot 010019, China.

7 E-mail addresses: wbingbing2008@126.com (B. Wang), zqlemail@imau.edu.cn (Q. Zhang).

8 Received: date; Accepted: date; Published: date

\section{Abstract}

The distribution and spatial variability of soil aggregates and their organic carbon and their responses to environmental factors in Daxing'anling forest region were studied by field investigation and laboratory analysis. In Daxing'anling forest region, 75 sampling points were set up based on kilometer grid, and the sample circle with radius of $17.85 \mathrm{~m}$ was set at each sampling point. In each circle, three samples of $0-20 \mathrm{~cm}$ topsoil were taken to determine soil chemical indexes, soil aggregates and their organic carbon content. The results showed that: (1) the soil aggregate content followed the order as $(0.25 \sim 2 \mathrm{~mm}$ aggregate $)>(<0.053 \mathrm{~mm}$ aggregate $)>(0.053 \sim 0.25 \mathrm{~mm}$ aggregate). The spatial autocorrelation of each fraction of aggregate were moderate, and they were affected by the structural factors such as climate, vegetation, soil and random factors such as human activities. The content of $0.25 \sim 2 \mathrm{~mm}$ and $<0.053 \mathrm{~mm}$ aggregates decreased gradually from north to south, while the content of $0.053 \sim 0.25 \mathrm{~mm}$ aggregates was opposite to them. (2) The organic carbon content of soil aggregates was mainly concentrated in the $0.25 \sim 2 \mathrm{~mm}$ large aggregates $(19.84 \mathrm{~g} / \mathrm{kg})$ with the contribution rate $50.39 \%$; the organic carbon contents of each fraction of aggregate showed high spatial autocorrelation which was mainly affected by structural factors; the spatial difference of soil aggregate content in each particle size was not significant, and the distribution was patchy. There was no significant spatial difference in the organic carbon contents of soil aggregate in different fractions with patch distribution characteristics. (3) Temperature had no significant effect on the formation and stability of soil aggregates, and precipitation is beneficial to the formation of micro-aggregates $<0.053 \mathrm{~mm}$; soil organic carbon was conducive to the cementation of small-sized aggregates into large aggregates, which had a positive effect on the stability of soil aggregates. There was a significant positive correlation between SOC and organic carbon of soil aggregates in different fractions, and the correlation degree was gradually weakened with the decrease of particle 
size; the contents of soil nitrogen, phosphorus, potassium and other nutrients could promote the organic carbon accumulation in soil aggregates. The results can provide the basis for the soil rational use and the carbon fixation capacity improvement of forest in Daxing'anling forest region.

Key words: Daxing'anling; soil aggregates; organic carbon; spatial variation

\section{Introduction}

Aggregates are soil structural units formed by condensation and cementation of mineral particles and soil organic matter (Ma et al., 2014; Yu et al., 2015). Their protection to soil organic carbon is an important mechanism for soil carbon pool stability (Six et al., 2004). Aggregates with different particle sizes play different roles in nutrient maintenance, supply and transformation (Liu et al.,2011), and their storage capacity for organic carbon is also different. Large aggregates generally can store more organic carbon (Wang et al., 2013). Due to the different protection mechanisms of soil aggregates to organic carbon, the stability of organic carbon in aggregates with different particle size is also different. Understanding the carbon distribution in aggregates with different particle sizes is an important means to study the dynamics of soil organic matter, and it is of great significance to study the role of organic carbon in the stability of aggregates (Christensen, 1992). Therefore, in recent years, the research on soil aggregates and their organic carbon has attracted much attention on different land use patterns (Mao et al., 2008; Zheng et al., 2010; Dong, 2011) and different forest types (Xie and Zhang, 2012; Yu et al., 2015; Liu et al.,2013; Zheng et al., 2019). The results showed that land use patterns could recombine and redistribute nutrients in soil aggregates by affecting soil structure, species, quantity and residual amount of vegetation litter, and soil microbial activities (Wang et al., 2003); the effect of forest types on soil aggregate content was mainly concentrated in large aggregate size (Sun et al., 2019). The above research on soil aggregates is basically reflected in a small scale, and the role of aggregates in the ecosystem cannot be fully understood. However, the 
formation of soil aggregates will be affected by soil characteristics, environmental factors and human factors (Jastrow, 1996). The research on the macro scale is helpful to reveal the spatial distribution and internal driving mechanism of soil aggregates, so as to comprehensively understand the formation and stability mechanism of soil aggregates (Ye et al., 2019).

The Daxing'anling possesses well preserved and largest original forest area in China with a forest coverage rate of $74.1 \%$. It is an important forestry and carbon storage base in China, and plays an irreplaceable role as a natural barrier. In this study, the distribution characteristics of soil aggregates and their organic carbon in Daxing'anling forest region were analyzed, and the effects of environmental factors on the stability of soil aggregates were discussed. The results can provide the basis for the rational utilization of soil and the improvement of forest carbon fixation capacity.

\section{Materials and methods}

\section{Study area}

Daxing' anling $\left(43^{\circ} \mathrm{N} \sim 53^{\circ} 30^{\prime} \mathrm{N}, 117^{\circ} 20^{\prime} \mathrm{E} \sim 126^{\circ} \mathrm{E}\right)$ is located in the northeast of China with the length of $1400 \mathrm{~km}$, width of $200 \mathrm{~km}$, elevation of $1100-1400 \mathrm{~m}$, and total area of $327200 \mathrm{~km}^{2}$. In summer, the marine monsoon is blocked on the east slope of the mountain, where there is much precipitation on the east slope, and the west slope is dry, with a mean annual precipitation of $500 \mathrm{~mm}$. The north part of the mountain range belongs to the continental monsoon climate of cold temperate zone with mean temperature in winter of $-28^{\circ} \mathrm{C}$, and there is a large area of permafrost distribution; the middle and south sections of the mountain are warm and dry with mean temperature of $-21^{\circ} \mathrm{C}$ in January, annual precipitation of $250-300 \mathrm{~mm}$, and less snow. The main tree species are Larix gmelinii, Pinus sylvestris, Picea koraiensis, Betula platyphylla, Quercus mongolica, Populus davidiana, etc. The soil types are mainly brown 
coniferous forest soil, dark brown soil, gray black soil, meadow soil and swamp soil.

\section{Plot setting and soil sampling}

The sampling points were set by kilometer grid in Daxing'anling forest area from July to August in 2017 (Fig. 1). 75 sampling points were set up at a distance of $60 \mathrm{~km}$ with the span of $47^{\circ} 48^{\prime} \sim 53^{\circ} 33^{\prime} \mathrm{N}$ from south to north and $118^{\circ} 19^{\prime} \sim 126^{\circ} 30^{\prime}$ E from east to west. A sample circle with a radius of $17.85 \mathrm{~m}$ was set up at each sampling point. In each circle, after removing surface litters, three soil samples of 0-20 cm topsoil with $500 \mathrm{~g}$ each were taken and put into plastic bags and brought back to the laboratory for analysis. Each tree and understory vegetation were investigated, and the altitude, slope, aspect and soil depth were recorded. According to the investigation, the Larix gmelinii and Betula platyphylla are the main tree species in the sample plot, along with Populus davidiana, Betula nigra, Quercus mongolica and Populus ussuriensis.

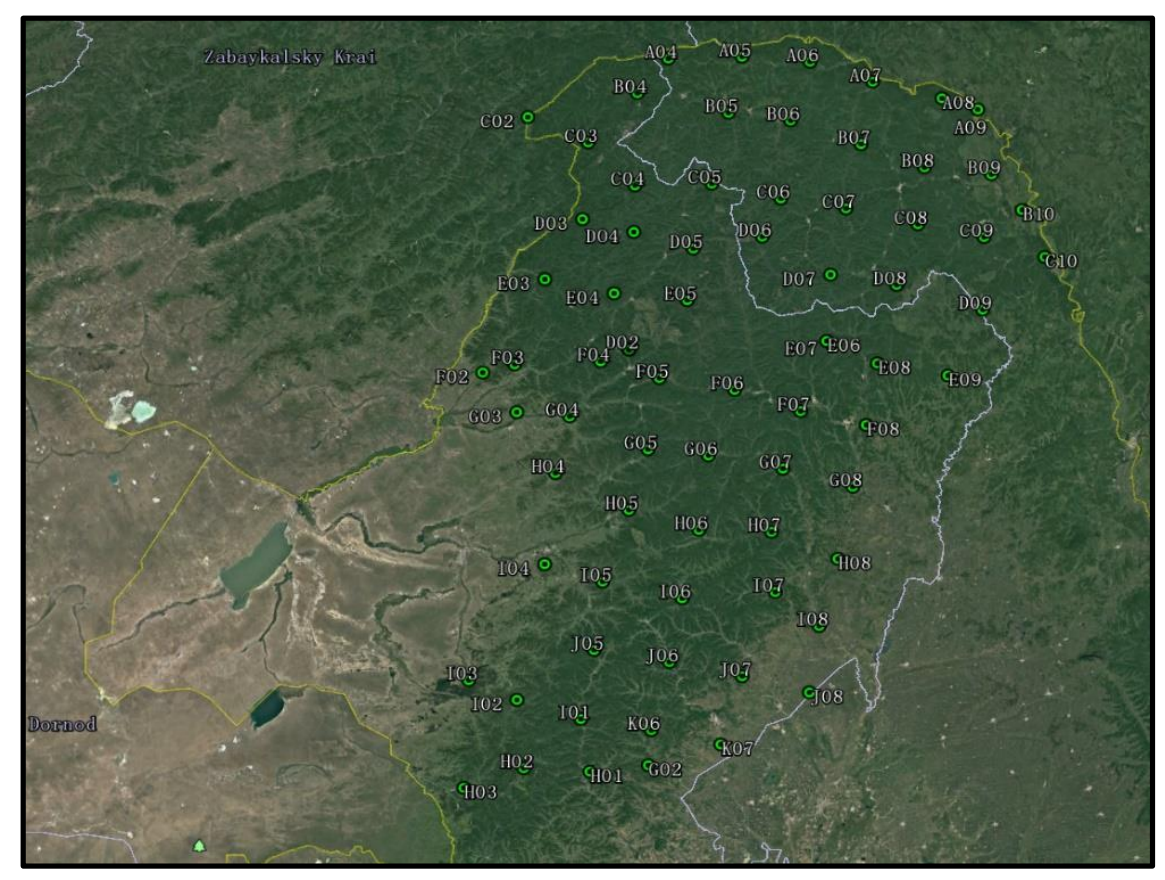

Fig.1 Distribution map of soil sampling points in Daxing'anling

\section{Soil sample determination}

The collected soil samples were taken back to the laboratory to remove the plant residues and gravel on the surface of soil samples, and then dried naturally for the 
determination of soil indexes. The $\mathrm{pH}$ value of soil was determined by $\mathrm{pH}$ meter $(\mathrm{w} / \mathrm{s}=5 / 1)$, total phosphorus (TP) was determined by acid dissolution spectrophotometry (HJ 632-2011F-HZ-DZ-TR-0057), ammonium nitrogen $\left(\mathrm{NH}_{4}{ }^{+}-\mathrm{N}\right)$, available potassium (AK) and available phosphorus (AP) were determined by combined extraction colorimetry (NY/T 1849-2010).

The microaggregate separation device was used to extract the aggregate fractions from the air-dried soil samples passing $2 \mathrm{~mm}$ sieve. The specific process was as follows (Elliott, 1986; Six et al., 2000): 50 glass beads were placed on the $0.25 \mathrm{~mm}$ filter membrane to disperse the soil particles by the water flow, so that the microaggregates and fine particles could pass through the $0.25 \mathrm{~mm}$ sieve, and the soil particles of $>0.25$ mm were separated; the microaggregates are collected on the $0.053 \mathrm{~mm}$ sieve, and then the dispersible silt and clay fractions were separated from the water stable microaggregates by wet sieving method; the obtained suspension was separated from the water stable microaggregates. After centrifugation, the easily dispersed silt and clay fractions $(<0.053 \mathrm{~mm})$ were obtained, and then dried at $60^{\circ} \mathrm{C}$ and weighed. The contents of organic carbon in soil aggregates with different particle sizes were determined by TOC elemental analyzer (SHIMADZU TOC-V CPH, Japan).

The temperature and precipitation data were generated by the climate model of ClimateAP for the years 2001-2010 (http://climateap.net/).

\section{Data calculation and statistics}

The indexes of mean weight diameter (MWD), geometric mean diameter (GMD) and fractal dimension (D) were selected to describe the stability of soil aggregates (Wang et al., 2019; Xu et al., 2018), and the calculation formulas were as follows:

$$
\begin{array}{r}
M W D=\sum_{i=1}^{n} W_{i} \bar{X}_{l} \\
G M D=\exp \left(\sum_{i=1}^{n} W_{i} \ln \bar{X}_{l}\right)
\end{array}
$$


142 Where, $\bar{X}_{l}$ is the mean diameter of $i$ particle size aggregate (in this study, the mean 143 diameter of aggregates at each particle sizes are $1.125,0.1515$ and $0.0265 \mathrm{~mm}$, 144 respectively), $X_{\max }$ is the mean diameter of maximum particle size (mm), $W_{i}$ is the mass of $i$ particle size aggregate $(\%), W_{0}$ is the total mass of soil sample $(\mathrm{g}), W_{r<\overline{X_{l}}}$ is the mass of aggregate smaller than $i$ particle size (g).

Based on the theoretical model and fitting parameters of semivariogram, the spatial characteristics of soil aggregates and their organic carbon in Daxing'anling forest region were studied by Kriging method. Semivariogram, also known as spatial variogram, is a method to measure the spatial correlation between samples. The semivariance value between each point depends on the distance between them (formula 4). Taking the variation function $\gamma(h)$ as the $Y$-axis and the sampling interval $h$ as the $X$-axis, the semivariance graphic can be drawn.

$$
r(h)=1 / 2 N(h) \times \sum_{i=1}^{N(h)}\left[Z\left(x_{i}\right)-Z\left(x_{i}+h\right)\right]^{2}
$$

Where: $\gamma(h)$ is the semivariance function; $N(h)$ is the sample number with interval $h$; $Z\left(x_{i}\right)$ and $Z\left(x_{i}+h\right)$ are the measured values of the regionalized variable $Z(x)$ at the spatial position $x_{i}$ and $x_{i}+H$, respectively. The semivariogram has three important parameters-nugget, sill and range, which are used to measure the spatial variation and correlation degree of regionalized variables and represented by $\mathrm{C}_{0}, \mathrm{C}_{0}+\mathrm{C}$ and $\mathrm{A}$, respectively (Wang et al., 2013).

One-way ANOVA was used to test the significant difference of soil aggregate and its organic carbon content among different particle size. Pearson correlation analysis and RDA analysis were used to analyze the relationships between soil aggregates and other indexes, and the software Origin Pro2019, Canoco4.5 and GS+9.0 were used to draw figures. 


\section{Results}

\section{Statistical characteristics of soil aggregates and its organic carbon}

\section{Composition characteristics of soil aggregates}

In Daxing' anling forest region, the proportion of aggregates with particle size of $0.25 \sim 2$ $\mathrm{mm}$ was the highest (46.14\%), followed by the aggregates with particle size $<0.053 \mathrm{~mm}$ (27.72\%), and the aggregates with particle size of $0.053 \sim 0.25 \mathrm{~mm}$ accounted for the lowest proportion (26.14\%) (Fig. 2). The variation coefficient of the proportion of each particle size ranged from $27.20 \%$ to $37.70 \%$. Aggregates with particle size $>0.25 \mathrm{~mm}$ are soil macroaggregates and an important part of soil aggregate structure; The higher its content is, the more stable the soil structure is (Ren et al., 2011). While the aggregates with particle size $<0.25 \mathrm{~mm}$ are soil microaggregates and the basis of microaggregates, it largely determines the number of soil aggregates, and their content and distribution have a significant impact on soil physical properties.

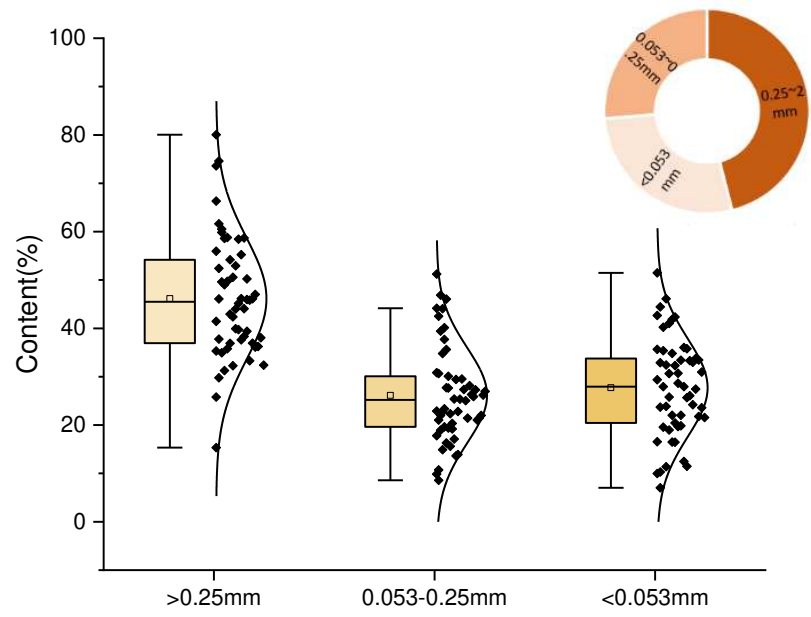

Fig.2 Soil aggregate composition in Daxing'anling

Stability characteristics of soil aggregates

Soil aggregate stability is an important indicator reflecting soil structure, which is closely related to soil erosion resistance and environmental quality (Liu et al., 2014). Mean weight diameter (MWD), geometric mean diameter (GMD) and fractal dimension (D) are important indexes for aggregate stability evaluation. The higher the 
proportion of aggregates with large particle size is, the larger MWD is, and the more stable soil aggregates are (Xie and Zhang, 2012); the smaller the fractal dimension of aggregates structure is, the better the structure and stability of soil is, and the stronger the corrosion resistance is (Gou et al., 2020). The MWD, GMD and D of soil aggregates in Daxing'anling forest region were $0.57 \mathrm{~mm}, 0.25 \mathrm{~mm}$ and 2.65, respectively (Fig.3).

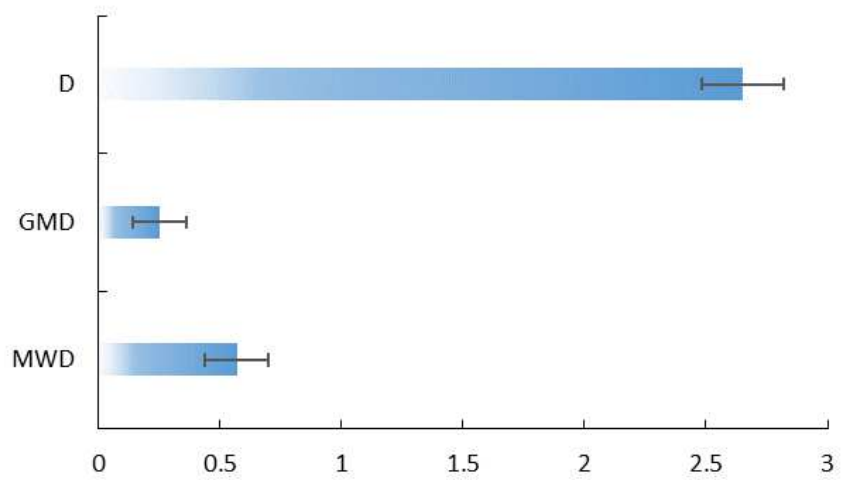

Fig.3 Stability characteristics of soil aggregates in Daxing'anling

Distribution characteristics of organic carbon in soil aggregates

It can be seen from Fig. 4 that the organic carbon content was mainly concentrated in the large aggregates of $0.25 \sim 2 \mathrm{~mm}$ with the content of $19.84 \mathrm{~g} / \mathrm{kg}$ and the contribution rate of $50.39 \%$; the order of the content was consistent with the proportion of the aggregate mass, and the organic carbon content in $0.053 \sim 2 \mathrm{~mm}$ aggregates was the lowest with the content of $7.29 \mathrm{~g} / \mathrm{kg}$ and the contribution rate of $18.33 \%$.

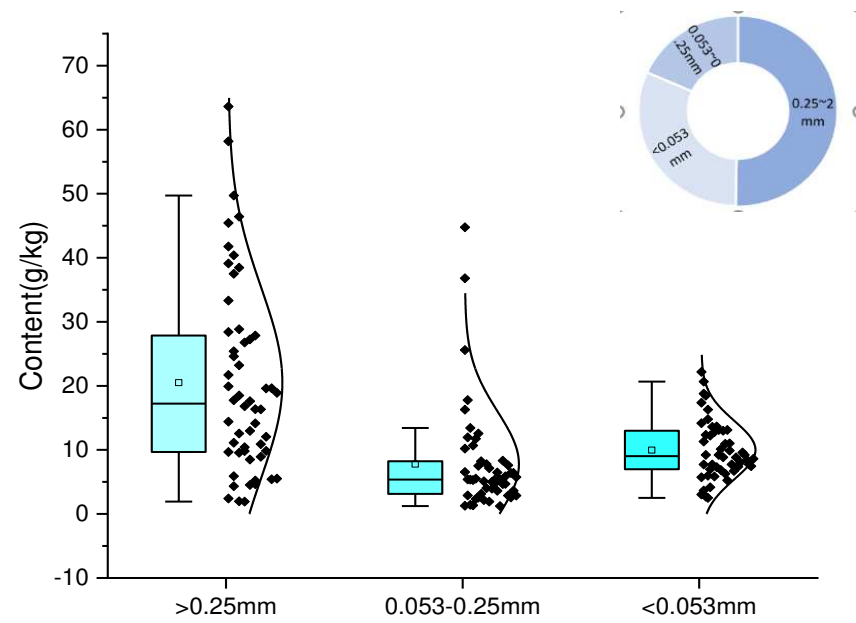

Fig.4 Content and contribution rate of soil aggregate organic carbon in Daxing'anling 
The correlations among different particle size aggregates and their stability indexes were showed in Fig.5. The content of $0.25 \sim 2 \mathrm{~mm}$ aggregates was significantly negatively correlated with the other two particle size aggregates $(P<0.01)$. The content of $0.053 \sim 0.25 \mathrm{~mm}$ aggregates was also negatively correlated with $<0.053 \mathrm{~mm}$ aggregates $(P>0.05)$. The content of $0.25 \sim 2 \mathrm{~mm}$ aggregates was significantly positively correlated with MWD and GMD $(P<0.01)$; the content of $0.053 \sim 0.25 \mathrm{~mm}$ aggregates was significantly $(P<0.05)$ or extremely significant $(P<0.01)$ negative correlation with MWD, GMD and D; the content of $<0.053 \mathrm{~mm}$ aggregates was negatively correlated with MWD and GMD $(P<0.01)$, and positively correlated with $\mathrm{D}(P<0.01)$. There was a significant positive correlation between MWD and GMD $(P<0.01)$, and a negative correlation between MWD and D.

Spatial characteristics of soil aggregates and its organic carbon

Geostatistics requires the sample data to meet the normal distribution. The K-S test 
requirements of geostatistical analysis, and could be used to the semivariance function fitting. While the organic carbon in $0.25 \sim 2 \mathrm{~mm}$ and $0.053 \sim 0.25 \mathrm{~mm}$ aggregates did not meet the requirements of normal distribution. After square root transformation and logarithmic transformation, the skewness values of organic carbon content in $0.25 \sim 2$ $\mathrm{mm}$ and $0.053 \sim 0.25 \mathrm{~mm}$ aggregate were smaller and more in line with the requirements of normal distribution.

The optimal semivariance theoretical models were selected by comparing the determination coefficients, as shown in Table 1. The optimal models of different aggregate indexes were different. The optimal models of $0.25 \sim 2 \mathrm{~mm}$ and $<0.053 \mathrm{~mm}$ aggregates were exponential models, while the optimal model of $0.053 \sim 0.25 \mathrm{~mm}$ aggregate was spherical model. The optimal models for organic carbon in aggregates of $0.25 \sim 2 \mathrm{~mm}$ and $0.053 \sim 0.25 \mathrm{~mm}$ were gaussian model, while the optimal model for organic carbon of aggregates $<0.053 \mathrm{~mm}$ was exponential model. Therefore, it was necessary to use different models to analyze the spatial variations of soil aggregates $(0$ $20 \mathrm{~cm}$ ) and its organic carbon contents in Daxing'anling forest region.

According to the semivariance function curve (Fig. 6), the semivariance function curves of soil aggregates in different particle sizes were not the same, and the curves of $0.25 \sim 2$ $\mathrm{mm}$ and $0.0530 .25 \mathrm{~mm}$ aggregates showed the characteristics of first rising and then flattening, while the semivariance value of $<0.053 \mathrm{~mm}$ aggregates increased with the increase of segmentation distance; With the decrease of aggregate particle size, the rising range of semivariance value gradually increased, and the stable range decreased gradually. It also can be seen that the semivariance function curve characteristics of soil aggregate organic carbon in different particle size fractions were relatively consistent with first increasing and then tending to be flat. According to the nugget sill ratio, the spatial autocorrelations of each aggregate fractions were moderate (Wang et al., 2013). 
275 While the organic carbon of each particle size aggregates showed high spatial autocorrelation. It indicated that the aggregates of all particle sizes were affected by the structural factors such as climate, vegetation, soil and random factors such as human activities; and the larger the particle size was, the greater the impact of random factors and the less the impact of structural factors were. The organic carbon contents of aggregates were mainly affected by climate, vegetation, soil and other structural factors. According to the results of semivariogram analysis, Kriging method was used for spatial interpolation to analyze the spatial distribution characteristics of soil aggregates and their organic carbon contents $(0-20 \mathrm{~cm})$ in Daxing'anling forest region (Fig. 7). It can be seen that there were some spatial differences in the content of soil aggregates in different particle sizes. On the whole, the contents of $0.25 \sim 2 \mathrm{~mm}$ and $<0.053 \mathrm{~mm}$ aggregates gradually decreased from north to south, while the contents of $0.053 \sim 0.25$ $\mathrm{mm}$ aggregate were on the contrary, and the zonal characteristic of $<0.25 \mathrm{~mm}$ microaggregates was more obvious. The spatial difference of organic carbon content in soil aggregates in Daxing'anling forest region was not significant and was distributed in patches. The organic carbon content of $<0.053 \mathrm{~mm}$ aggregates in the northern forest area was significantly lower than that in the southern forest region.
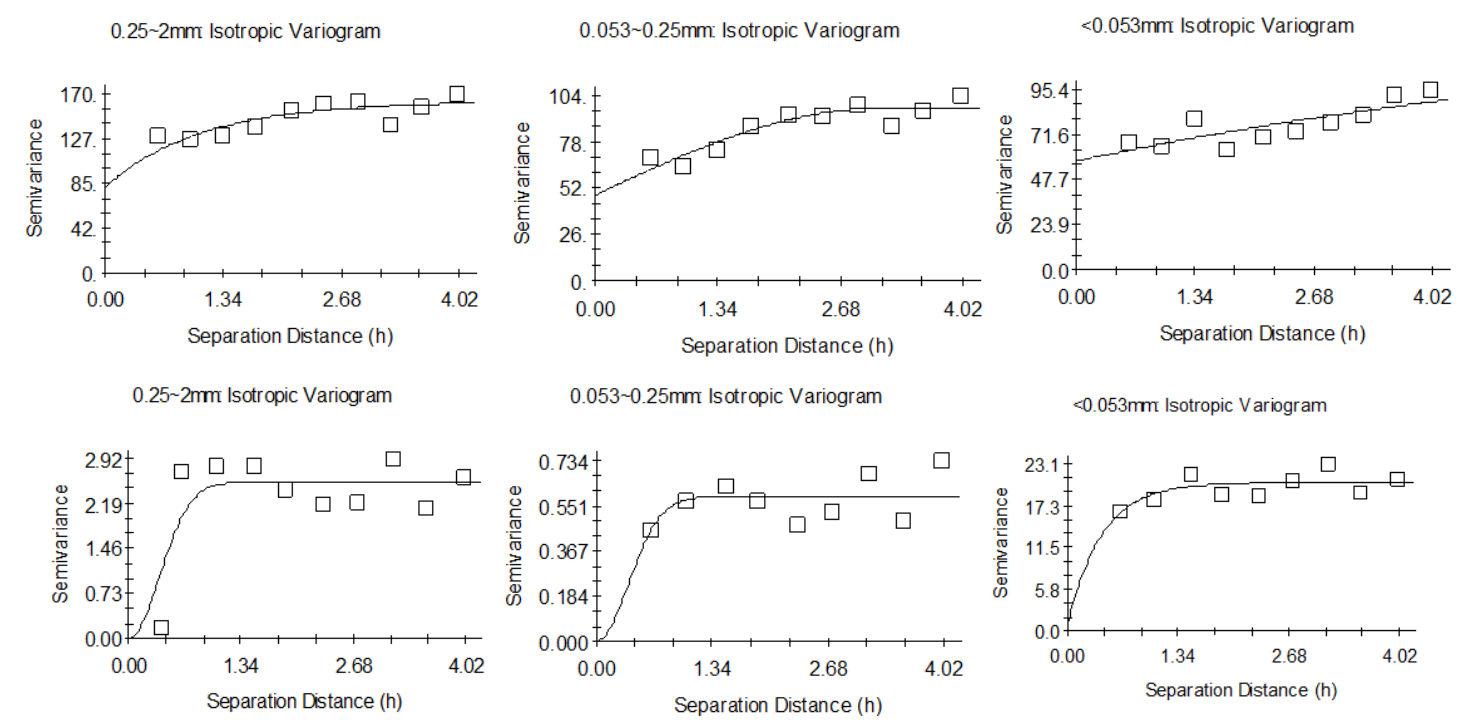

Fig.6 Semivariograms of soil aggregates in different particle sizes 
Table 1 Optimal model list for soil aggregates in different particle sizes

\begin{tabular}{|c|c|c|c|c|c|c|c|}
\hline \multicolumn{2}{|c|}{ Index } & $\begin{array}{l}\text { Theoretical } \\
\text { model }\end{array}$ & $\begin{array}{c}\text { Nugget } \\
\mathrm{C}_{0}\end{array}$ & $\begin{array}{l}\text { Still } \\
\mathrm{C}+\mathrm{C}_{0}\end{array}$ & $\begin{array}{l}\text { Nugget sill } \\
\quad \text { ratio } \\
\mathrm{C}_{0} /\left(\mathrm{C}+\mathrm{C}_{0}\right)\end{array}$ & $\begin{array}{l}\text { Rang } \\
A\left({ }^{\circ}\right)\end{array}$ & $\begin{array}{c}\text { Coefficient of } \\
\text { determination } R^{2}\end{array}$ \\
\hline \multirow{3}{*}{ Aggregates } & $0.25 \sim 2 \mathrm{~mm}$ & iential & 81.3 & 162.7 & $50.0 \%$ & 109 & 06 \\
\hline & $0.053 \sim 0.25 \mathrm{~mm}$ & Spherical & 48.2 & 96.5 & $49.9 \%$ & 3.06 & 0.822 \\
\hline & $<0.053 \mathrm{~mm}$ & Exponential & 54.7 & 133.35 & $41.0 \%$ & 7.50 & 0.652 \\
\hline \multirow{3}{*}{$\begin{array}{l}\text { Aggregate } \\
\text { organic } \\
\text { carbon }\end{array}$} & $0.25 \sim 2 \mathrm{~mm}$ & Gaussian & 0.001 & 2.540 & $0.04 \%$ & 0.52 & 0.692 \\
\hline & $0.053 \sim 0.25 \mathrm{~mm}$ & Gaussian & 0.0020 & 0.5860 & $0.34 \%$ & 0.52 & 0.210 \\
\hline & $<0.053 \mathrm{~mm}$ & Exponential & 0.8100 & 20.500 & $3.95 \%$ & 0.41 & 0.448 \\
\hline
\end{tabular}

307

308

309

310
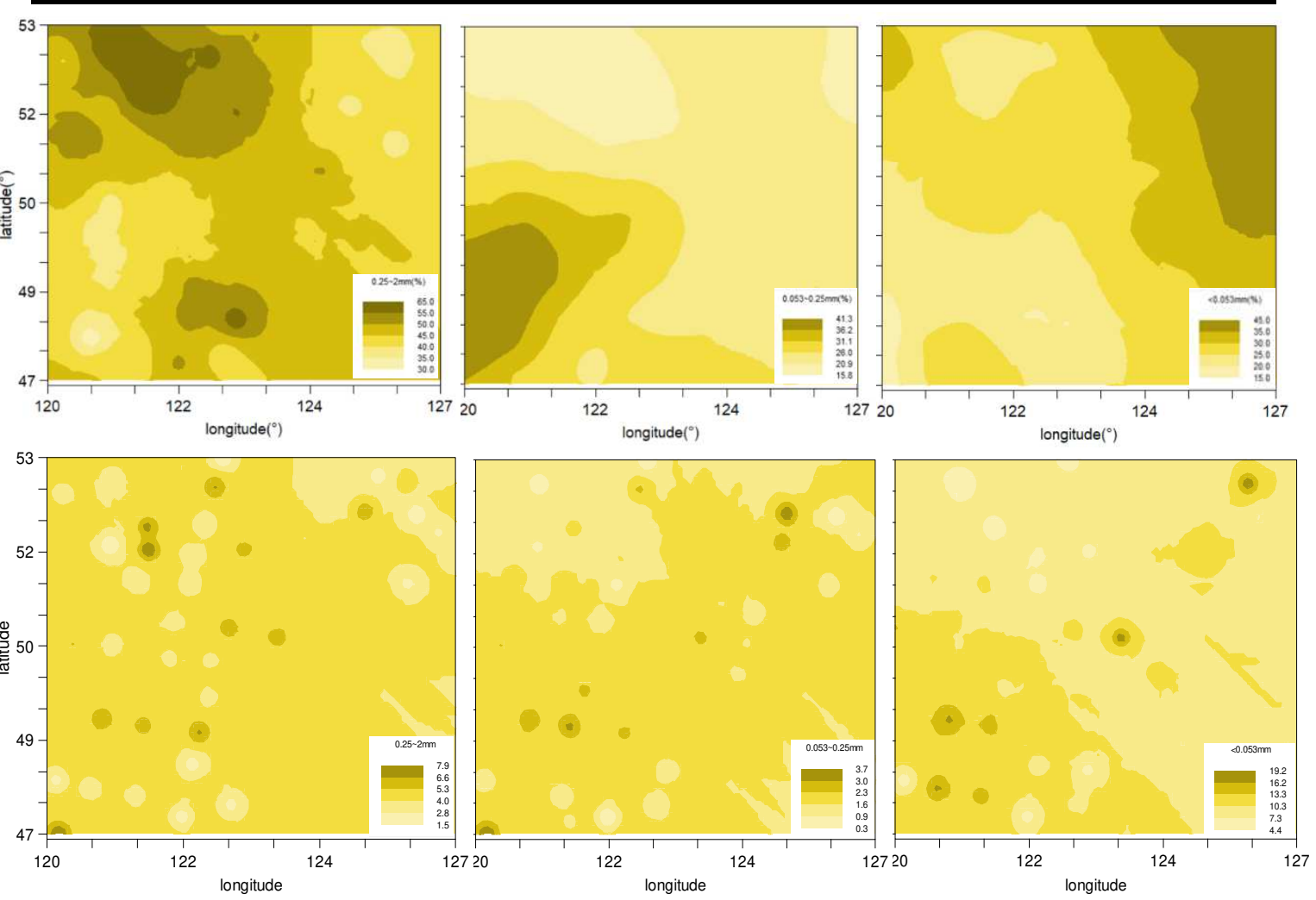

Fig.7 Spatial distribution of soil aggregates in different particle sizes

\section{Influencing factor analysis of soil aggregate and its organic carbon}

The effects of environmental factors on the soil aggregates and their organic carbon

were analyzed by RDA analysis (Fig. 8). There was no significant correlation between

soil aggregate factors and temperature, indicating that the influence of temperature on

soil aggregate was not obvious. The content of soil macroaggregate $(0.25 \sim 2 \mathrm{~mm})$ was

significantly positively correlated with $\mathrm{SOC}$ and negatively correlated with $\mathrm{pH}$; the content of microaggregates $(0.053 \sim 0.25 \mathrm{~mm})$ was only significantly negatively correlated with precipitation; the content of microaggregates $(<0.053 \mathrm{~mm})$ was 
and precipitation. The above results indicated that there were some differences in the correlation between soil aggregates and various factors.

SOC had a significantly positive correlation with MWD and GMD, and a significantly negative correlation with $\mathrm{D}$ value. The relationship between each stability index and other factors was not the same. MWD and GMD were negatively correlated with $\mathrm{pH}$, and precipitation had a significant positive effect on $\mathrm{D}$. The above analysis showed that climate factors and soil chemical properties had a certain impact on the stability of soil aggregates.

There was a significant positive correlation between SOC and organic carbon of different particle size aggregates $(P<0.01)$. The correlation between SOC and organic carbon of $0.25 \sim 2 \mathrm{~mm}$ aggregates was the highest $(\mathrm{r}=0.928)$, and the correlation degree gradually decreased with the decrease of particle size. There was a significant positive correlation between soil aggregate organic carbon and TP; $0.25 \sim 2 \mathrm{~mm}$ and $<0.053 \mathrm{~mm}$ aggregates had significant positive correlation with $\mathrm{NH}_{4+-} \mathrm{N}$; Organic carbon contents in $0.25 \sim 2 \mathrm{~mm}$ and $0.053 \sim 0.25 \mathrm{~mm}$ aggregates had significant positive correlation with AK; Organic carbon content in $0.053 \sim 0.25 \mathrm{~mm}$ aggregate also had a significant negative correlation with precipitation. The results showed there were some differences in the correlation between soil aggregate carbon content and various factors, and soil chemical properties had certain effects on soil aggregate organic carbon.
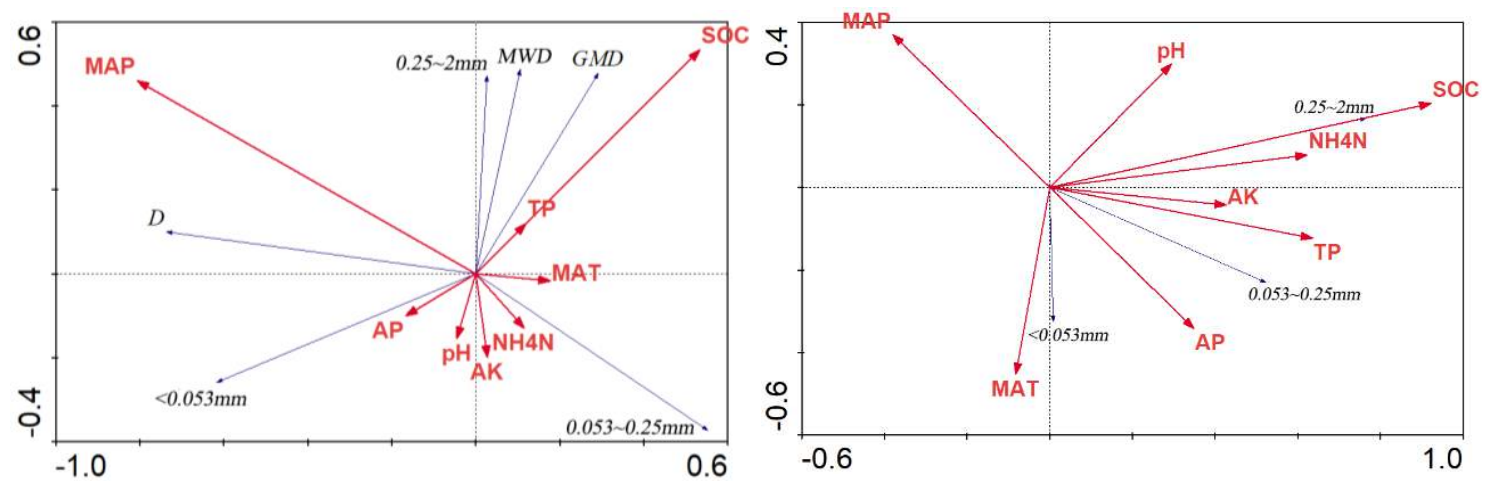

Fig. 8 Correlations between soil aggregate factors and soil physicochemical factors, climatic factors 


\section{Discussions}

\section{Statistical characteristics of soil aggregates and their organic carbon}

The soil aggregate content of each particle size in Daxing'anling forest region followed the order of $(0.25 \sim 2 \mathrm{~mm})>(<0.053 \mathrm{~mm})>(0.053 \sim 0.25 \mathrm{~mm})$, which was consistent with previous research results (Cheng et al., 2013; Zhao et al., 2018). Studies had shown that roots and fungal hyphae were the main cementing agents for macroaggregates, while humic organic matter was the cementing agent for microaggregates (Tisdall and Oades, 1982). Forest soil was dominated by macroaggregates, which was directly related to the role of plant roots. Plant roots, including dead roots, promoted the formation and stability of soil aggregates by winding and connecting soil particles and releasing secretions (Yuan et al., 2018). The composition of soil aggregates was closely related to the quality of soil structure. The content of aggregates $>0.25 \mathrm{~mm}$ can reflect the quality of soil to a certain extent. The higher the content, the more stable the soil aggregates were, the better the soil structure and quality were (Barthes and Roose, 2002; Ma et al., 2013).

The stability of soil aggregates was the key to reflect the physical protection of soil aggregates on organic carbon, which can be measured by MWD, GMD and D. The higher the MWD and GMD values were, the higher the aggregation degree of the aggregates was, the more stable the aggregates were and the better the soil structure was. The smaller the D value was, the smaller the dispersibility and erodibility of soil aggregates were, and the better the stability of soil structure was. In Daxing'anling forest region, the vegetation formed for a long time and grew well, the humification degree of soil organic matter and the proportion of persistent organic medium were high, so the stability of soil aggregate was high.

The organic carbon of soil aggregates in Daxing'anling forest region was mainly 
concentrated in $0.25 \sim 2 \mathrm{~mm}$ size aggregates, accounting for $50.39 \%$, which indicated that this particle size aggregate was an important material condition for soil fertility, which was consistent with the research results of Mikha and Rice (2004), Wang et al. (2019) and Zhao et al. (2019), and proved that the large aggregates contain more organic carbon than the microaggregates. Woodland can promote the formation of large aggregates from silt and clay particles and microaggregates, at the same time, make more soil organic carbon accumulate to large aggregates, which made large aggregates become the main body of carbon storage. However, the formation of microaggregates was often accompanied by the decomposition of particulate organic matter (iPOM) in large aggregates, which led to the transformation of large aggregates into microaggregates (Jastrow et al., 1996; Six et al., 2004). Therefore, microaggregates contain low carbon content.

\section{Spatial variability of soil aggregates and their organic carbon}

Based on Geostatistics theory and Kriging spatial interpolation method, the results showed that the aggregate content of soil in Daxing'anling forest region obeyed normal distribution statistically, and there were some spatial differences. On the whole, the content of $0.25 \sim 2 \mathrm{~mm}$ and $<0.053 \mathrm{~mm}$ aggregates decreased gradually from north to south, while the content of $0.053 \sim 0.25 \mathrm{~mm}$ aggregates was the opposite. The content of aggregates in each particle size showed moderate spatial autocorrelation, which indicated that it was affected by structural factors such as climate, vegetation and soil and random factors such as human activities. The larger the particle size was, the greater the impact of random factors was. In the north of Daxing'anling, there was the largest virgin forest in China. Where the forest soil was in a natural state for a long time without human interference, and the vegetation grown vigorously and the litter layer was thick, which can effectively slow down the erosion of surface soil by precipitation and reduce 
the impact of rainfall on $>0.25 \mathrm{~mm}$. In the south, the influence of human activities was more obvious. Frequent human disturbance will lead to the disintegration of large aggregates with relatively poor stability, and increase the content of microaggregates and silt-clay components. The spatial autocorrelation of organic carbon in each size fraction of aggregates was high, indicating that it was mainly affected by structural factors.

\section{Influencing factors of soil aggregates and their organic carbon}

There were certain correlations among the characteristic values of soil aggregates. The content of soil macroaggregates $(>0.25 \mathrm{~mm})$ was significantly positively correlated with MWD and GMD, and negatively correlated with D. The correlation between the content of microaggregates $(<0.25 \mathrm{~mm})$ and various stability indexes was contrary to that of large aggregates, indicating that the stability of soil aggregates could be improved by increasing the content of large-sized aggregates in soil. There was a significant positive correlation between the organic carbon of different particle size aggregates $(P<0.01)$. Macroaggregates can combine a large amount of organic carbon, and promote the formation of micro aggregates through the interaction between organic matter and soil environment, thus providing conditions for the long-term retention of organic carbon in microaggregates (Six et al., 2000).

Studies have shown that the main influencing factors of soil aggregates are soil texture, clay mineral type, calcium, magnesium and other cation content, iron and aluminum oxides and soil organic carbon ( $\mathrm{Li}$ et al., 2009). At the same time, the formation and evolution of soil aggregates with different particle sizes were also significantly affected by various biological factors in the soil, including roots, soil animals, soil microorganisms and their metabolites (Yuan et al., 2011). Soil aggregate can stabilize and protect soil organic carbon, which is the place where soil organic carbon exists. 
Soil organic carbon is the cementation material of soil aggregate, and the two are inseparable. The results showed that there was a significant positive correlation between SOC and $0.25 \sim 2 \mathrm{~mm}$ aggregates, but a significant negative correlation with $<0.053 \mathrm{~mm}$ aggregates. The results show that soil organic matter is beneficial to the cementation of small-sized aggregates into large aggregates. The higher the content of soil organic carbon, the higher the content of large aggregates. There was a significant positive correlation between SOC and MWD and GMD, and a significant negative correlation with fractal dimension D. The results show that soil organic carbon has a positive effect on the stability of soil aggregates. The higher the soil organic carbon content, the larger the average weight diameter and geometric average diameter of soil aggregates, the smaller the fractal dimension, so the better the structure and stability of soil and the stronger the anti-erosion ability. This is consistent with the research results of Zhao et al (2019) and Wang et al (2019) on soil aggregates and their stability of different forest types. Organic matter, as the main binding material, is likely to play an important role in the formation of soil aggregates in Daxing'anling forest region. As an important cementation material, organic matter can enhance the binding force between aggregates. There are many litters on the forest surface. In the process of litter decomposition and transformation into organic carbon, micro aggregates form large aggregates through organic matter cementation, With the formation of large aggregates, the average weight diameter increases, and the soil structure gradually tends to be stable (Zheng et al., 2010). Therefore, in the process of forest management, we can increase the content of soil organic carbon and improve the stability of aggregates, so as to improve the ecological function of the forest. Soil aggregate content, MWD and GMD of $0.25-2 \mathrm{~mm}$ soil in Daxing'anling Forest Region were significantly negatively correlated with $\mathrm{pH}(P<0.01)$, indicating that acid soil is more conducive to the 
formation of large aggregates and the stability of soil structure (Zhao et al., 2019). The results showed that there was a significant positive correlation between the content of $<0.053 \mathrm{~mm}$ aggregates and precipitation $(P<0.01)$, indicating that water can promote the formation of clay aggregates.

Soil humus is not only the main cementing agent of soil aggregates, but also an important place for the preservation of soil organic matter. It is of great significance to soil fertility and structural characteristics, especially in improving the stability of soil aggregates (Gou et al., 2020). Soil organic carbon is an important factor in the formation and stability of soil aggregates, and one of the most important ways to fix organic carbon occurs in the process of cementation and agglomeration of soil particles with different particle sizes (Dou et al., 2011). There was a significant positive correlation between SOC content and soil aggregate organic carbon $(P<0.01)$. The results showed that the organic carbon content of soil aggregates was closely related to the SOC content, and SOC had an important influence on the distribution of organic carbon among different particle fractions. Stewart et al. (2008) pointed out that micro aggregates as a whole showed more linear relationship with total organic carbon. The effects of total phosphorus, ammonium nitrogen, available potassium and other nutrient factors on soil aggregate organic carbon were consistent and positively correlated, indicating that soil nutrients can promote the increase of soil aggregate organic carbon to a certain extent.

\section{Conclusion}

The distribution of soil aggregates in Daxing'anling forest region was $(0.25 \sim 2 \mathrm{~mm}$, $46.14 \%)>(<0.053 \mathrm{~mm}, 27.72 \%)>(0.053 \sim 0.25 \mathrm{~mm}, 26.14 \%)$. All aggregates showed moderate spatial autocorrelation, and were affected by structural factors such as climate, vegetation and soil and random factors such as human activities. The larger the particle size, the greater the impact of random factors. The content of $0.25 \sim 2 \mathrm{~mm}$ aggregates 
and $<0.053 \mathrm{~mm}$ aggregates decreased gradually from north to south, while the content of $0.053 \sim 0.25 \mathrm{~mm}$ aggregates was just the opposite.

The organic carbon content of soil aggregates in Daxing'anling forest region was mainly concentrated in large aggregates with particle size of $0.25 \sim 2 \mathrm{~mm}(50.39 \%)$; The organic carbon content of soil aggregates with particle size of $0.053 \sim 2 \mathrm{~mm}$ was the lowest $(18.33 \%)$. The organic carbon of each particle size aggregate showed high spatial autocorrelation, which was mainly affected by structural factors. The spatial difference of organic carbon content in soil aggregates of each particle size was not significant, which was distributed in patches.

Temperature had no significant effect on the formation and stability of soil aggregates, precipitation was beneficial to the formation of $<0.053 \mathrm{~mm}$ microaggregates; Soil organic carbon had a significant positive correlation with $0.25 \sim 2 \mathrm{~mm}$ aggregate content, MWD and GMD. Soil organic matter was conducive to the cementation of small aggregates into large aggregates, which played a positive role in the stability of aggregates. There was a significant positive correlation between SOC and organic carbon in soil aggregates of each particle size, and the correlation degree decreased gradually with the decrease of particle size; The contents of soil nutrients such as nitrogen, phosphorus and potassium could promote the accumulation of organic carbon in soil aggregates.

\section{Acknowledgement}

We are grateful for the support from Inner Mongolia Daxing'an Mountains Forest Ecosystem National Field Science Observation and Research Station. This work was financially supported by the Key Technologies Research and Development Program, China (grant numbers 2017YFC0504003 and 2017YFC050410302); the Natural Science Foundation of Inner Mongolia, China (grant number 2018MS03049). 


\section{References}

Barthes B, Roose E (2002) Aggregate stability as an indicator of soil susceptibility to runoff and erosion; validation at several levels. Catena 47: 133-149

Cheng M. Zhu QL, Liu L, An SS (2013) Effects of vegetation on soil aggregate stability and organic carbon sequestration in Ningxia Loess Hilly Region of northwest China. Acta Ecologica Sinica 33(9): 2835-2844.

Christensen BT (1992) Physical fractionation of soil and organic matter in primary particle size and density separates. Advances in Soil Science 20: 2-90

Dong LL (2011) Characteristics of soil water stable aggregates under different land-use types. Scientia Silvae Sinicae 47(4): 95-100.

Dou S, Li K, Guan S (2011) A review on organic matter in soil aggregates. Acta Pedologica Sinica 48(2): 412-418

Elliott ET (1986) Aggregate Structure and Carbon, Nitrogen, and Phosphorus in Native and Cultivated Soils. Soil Science Society of America Journal 50: 627-633

Gou TX, Liu H, Shuai W, Jiang XH, Li J (2020) Characteristics of soil aggregate at different altitude gradients in high-frigid mountain of west Sichuan region. Research of Soil and Water Conservation 27(1): 47-53.

Jastrow JD 1996 Soil aggregate formation and the accrual of particulate and mineral-associated organic matter. Soil Biology \& Biochemistry 28: 665-676

Li JT, Zhong XL, Zhao QG (2009) Influence factors of soil aggregate stability under disturbing of cultivation and fertilization. Ecology and Environmental Sciences 18(6): 2354-2359.

Liu WL, Wu JG, Fu MJ, Liang YJ, Zhao XY (2014) Effect of different cultivation years on composition and stability of soil aggregate fractions in orchard. Journal of Soil and Water Conservation 28(1): 129-135.

Liu Y, Cha TG, Wang YK, Wang GM (2013). Soil aggregate stability and soil organic carbon characteristics in Quercus variabilis and Pinus tabulaeformis plantations in Beijing area. Chinese Journal of Applied Ecology 24(3): 607-613.

Liu ZL, Yu WT, Zhou H, Xu YG, Huang BT (2011) Effects of long-term fertilization on aggregate size distribution and nutrient content. Soils, 43(5): 720-728

Ma RP, An SS, Dang TH, Dai XL (2014) Soil organic carbon and enzymatic activity in aggregates of soils under different plant communities in hilly-gully regions of Loess Plateau. Acta Pedologica Sinica 51(1): 104-113

Ma RP, Liu L, An SS, Dang TH (2013) Soil organic carbon and its fractions in aggregates under different plant communities in the hillgully region of the Loess Plateau. Chinese Journal of EcoAgriculture 21(3): 324-332.

Mao YL, Yang YS, Xing SH, Chen GS, Cui JC (2008) Effects of land use on soil organic carbon in water-stable aggregates. Journal of Soil and Water Conservation 22(4): 132-137.

Mikha MM, Rice CW (2004) Tillage and manure effects on soil and aggregate-associated carbon and nitrogen. Soil Science Society of America Journal 68: 809-816

Ren ZJ, Luo YJ, Wei CF (2011) Progress in the study on field soil aggregate. Journal of Anhui Agriculture Science 39(2): 1101-1105

Six J, Bossuyt H, Degryze S, Denef K (2004) A history of research on the link between (micro)aggregates, soil biota, and soil organic matter dynamics. Soil \& Tillage Research 79: 7-31

Six J, Elliott ET, Paustian K (2000) Soil macroaggregate turnover and microaggregate formation: a mechanism for C sequestration under no-tillage agriculture. Soil Biology \& Biochemistry 32: 2099-2103

Stewart CE, Plante AF, Paustian K, Conant RT, Six J (2008) Soil carbon saturation: linking concept and measurable carbon pools. Soil Science Society of America Journal 72: 379-392

Sun YT, Tian Y, Zhang JY (2019) Soil aggregates stability and organic carbon distribution of four plantations in sandy land of Henan southeastern area. Forest Inventory and Planning 44(4): 42-48 
Tisdall JM, Oades JM (1982) Organic matter and water-stable aggregates in soils. European Journal of Soil Science 33: 141-163

Wang B, An HJ, Lv CW (2013) Spatial variations of dissolved oxygen in Hulun Lake using geostatistics and GIS technology. Arid Land Geography, 36(6): 1103-1110

Wang FH, L S, Huang R, Gao M, Wang ZF, Xu C (2019) Distribution of organic carbon in soil aggregates from four kinds of forest vegetation on Jinyun Mountain. Environ Sci 40 (3): 1504 -1511.

Wang HJ, Li XW, Shi XZ, Yu DS (2003) Distribution of soil nutrient under different land use and relationship between soil nutrient and soil granule composition. Journal of Soil and Water Conservation 17(2): 44-46.

Wang XY, Zhou C, Feng WH, Chen JL, Jiang XH (2019) Changes of soil aggregates and its organic carbon in Chines Fir plantations with different forest ages. Journal of Soil and Water Conservation 33(5): 126-131.

Wang Y, Liu JS, Wang QY (2013) The Effects of freeze-thaw processes on soil aggregates and organic carbon. Ecology and Environmental Sciences 22(7): 1269-1274.

Xie XJ, Zhang J (2012) Soil aggregates and fractal features under different styles of Eucalyptus grandis plantations. Journal of Soil and Water Conservation 26(6): 175-179.

Xu HW, Wu Y, Qiao LL, Li YZ, Xue, Qu S, Q (2018) Soil aggregate and stability in the ecological restoration process under different vegetation zones and Loess Plateau. China Environmental Science 38(6): 2223-2232

Ye LP, Tan WF, Fang LC, Zhao W (2019) Research advances in spatial variability of soil aggregate by using geostatistics. Science of Soil and Water Conservation 17(2): 146-153.

Yu HY, Gong RN, Zhou Y, Cha TG, Nie LS, Lv ZY (2015) Characteristic of soil aggregate stability and soil organic carbon under four typical artificial plantations in Beijing Badaling mountain area. Journal of Soil and Water Conservation 29(5): 162-166.

Yuan YR, Han XZ, Li LJ, Ding XL (2011) Effects of soluble root exudates on microbial activity and aggregate stability of black soils. Journal of Soil and Water Conservation 25(6): 96-99.

Yuan YR, Li N, Zou WX, You MY, Han XZ, Ma DL (2018) Distribution characteristics of organic carbon in aggregates of soils of three ecosystems in typical Mollisols of Northeast China. Acta Ecologica Sinica 38(17): 6025-6032.

Zhao YP, Meng MJ, Zhang JC, Ma JY, Liu SL (2018) Study on the composition and stability of soil aggregates of the main forest stands in Fengyang Mountain, Zhejiang Province. Journal of Nanjing Forestry University 42(5): 88-94.

Zheng XB, Zhang X, Han SJ (2019) Changes of soil aggregate size composition and organic carbon content at different succession stages of broadleaved Korean pine forest in Changbai Mountain, China. Chinese Journal of Applied Ecology 30(5): 134-143.

Zheng ZC, He SQ, Wang YD, Li TX, Zhang XZ, Xu Y (2010) Distribution feature of soil nutrients in aggregate under different land use [J]. Journal of Soil and Water Conservation 24(3): 170-174. 